\title{
Mapping and validation of the genes for resistance to Pyrenophora teres f. teres in barley (Hordeum vulgare L.)
}

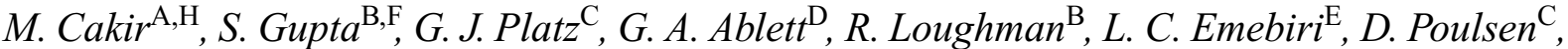

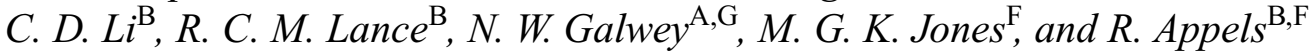

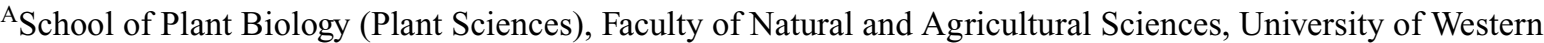 \\ Australia, Crawley, WA 6907, Australia. \\ ${ }^{\mathrm{B}}$ Crop Improvement Institute, Department of Agriculture, South Perth, WA 6151, Australia. \\ ${ }^{\mathrm{C}}$ Queensland Department of Primary Industries, Hermitage Research Station, Warwick, Qld 4370, Australia. \\ ${ }^{\mathrm{D}}$ Centre for Plant Conservation Genetics, Southern Cross University, Lismore, NSW 2480, Australia. \\ ${ }^{\mathrm{E}}$ Department of Primary Industries, Victorian Institute for Dryland Agriculture, \\ Private Bag 260, Horsham, Vic. 3401, Australia. \\ FState Agricultural Biotechnology Centre, Murdoch University, Murdoch, WA 6150, Australia. \\ GPresent address: Oxagen Limited, 91 Milton Park, Abingdon, Oxfordshire, OX14 4RY England. \\ ${ }^{\mathrm{H}}$ Corresponding author, present address: WA State Agricultural Biotechnology Centre, Division of Science \\ and Engineering, Murdoch University, Murdoch, WA 6150, Australia; email: mcakir@murdoch.edu.au
}

\begin{abstract}
Identification and deployment of disease resistance genes are key objectives of Australian barley breeding programs. Two doubled haploid (DH) populations derived from Tallon $\times$ Kaputar (TK) and VB9524 $\times$ ND11231 (VN) crosses were used to identify markers for net type net blotch (NTNB) (Pyrenophora teres f. teres). The maps included 263 and 250 markers for TK and VN populations, respectively. The TK population was screened with 5 pathotypes and the VN population with 1 pathotype of NTNB as seedlings in the glasshouse. In addition, the TK population was subjected to natural infection in the field at Hermitage Research Station, Qld. Analyses of the markers were performed using the software packages MapManager and Qgene. One region on chromosome $6 \mathrm{H}$ was strongly associated with resistance to NTNB in both populations $\left(R^{2}=83 \%\right.$ for TK and $66 \%$ for VN). In the TK population, 2 more quantitative trait loci (QTLs) were identified on chromosomes $2 \mathrm{H}$ and $3 \mathrm{H}$, with $R^{2}$ values of $30 \%$ and $31 \%$, respectively. These associations were consistent over all pathotypes studied during the seedling stage. The same QTL on chromosome $6 \mathrm{H}$ was also found to be highly significantly associated $\left(R^{2}=65 \%\right)$ with the adult plant (field) response in the TK population. There are several very closely linked markers showing strong associations in these regions. Association of the 4 markers on chromosome 6H QTL with resistance to the NTNB has been validated in 2 other DH populations derived from barley crosses Pompadour $\times$ Stirling and WPG8412 $\times$ Stirling. These markers present an opportunity for marker assisted selection of lines resistant to NTNB in barley breeding programs.
\end{abstract}

Additional keywords: SSR, AFLP, genetic mapping, net type net blotch.

\section{Introduction}

Net blotch, caused by Pyrenophora teres Drechs. (anamorph: Drechslera teres (Sacc.) Shoemaker), is a major disease in most barley-growing areas in Australia and around the world. Pyrenophora teres f. teres causes a net type lesion, which is characterised by dark brown blotches with a net-like pattern, sometimes accompanied by chlorosis (SmedegardPetersen 1971; Khan and Tekauz 1982). Host reaction is influenced by the genotype and the infection environment (Khan and Boyd 1969).

Pyrenophora teres is a highly variable pathogen (Pon 1949; Afanasenko and Levitin 1979; Tekauz 1990;
Steffenson and Webster 1992). Thirteen pathotypes of net type net blotch have been identified in Australia (Platz et al. 2000). Due to high variability of the pathogen and reduced tillage farming practices, the incidence of net type net blotch (NTNB) in Australia has increased over the years, with estimated yield losses of $>30 \%$ (Khan 1987). Consequently, a major objective of Australian barley breeding programs is to increase resistance to this disease in local barley cultivars.

Several studies have explored the inheritance of resistance to NTNB. In most cases, 1-3 genes have been identified against different pathotypes of the fungus. In Canada and Egypt, one dominant gene for resistance was detected 
(Buchannon and McDonald 1965), whereas in Australia, Khan and Boyd (1969) identified 2 dominant resistance genes. More recently, numerous genes were identified in different barley lines from around the world (Wilcoxson et al. 1992; Douiyssi et al. 1996; Ho et al. 1996; Afanasenko et al. 1999; Jonsson et al. 1999). A current study of barley genotypes using NTNB isolates from Western Australia, Queensland, and South Australia, has detected more than 6 genes for resistance (Gupta et al. 2002).

Molecular markers were used to determine the number of quantitative trait loci (QTLs) involved in resistance to NTNB. Steffenson et al. (1996) mapped 3 QTLs for seedling resistance and 7 for adult plant resistance. The seedling and adult plant resistances were located on different chromosomes. In a doubled haploid $(\mathrm{DH})$ population from the cross of Igri $\times$ Franka, a single dominant gene for resistance was located on chromosome 3H (Graner et al. 1996). Richter et al. (1998) found 12 QTLs conditioning seedling resistance in an $\mathrm{F}_{2}$ population derived from the susceptible barley cultivar Arena and the resistant Ethiopian landrace Hor 9088. Spaner et al. (1998) mapped 3 QTLs on chromosomes $4 \mathrm{H}, 5 \mathrm{H}$, and $6 \mathrm{H}$ in a $\mathrm{DH}$ population of the cross Harrington $\times$ TR306. Manninen et al. (2000) used retrotransposon-based molecular markers (retrotransposonmicrosatellite amplified polymorphism and interretrotransposon amplified polymorphism) and identified a major locus on chromosome $6 \mathrm{H}$ accounting for $65 \%$ of the response variation in a cross between the resistant line CI9819 and the susceptible cultivar Rolfi. These studies indicate that many genes have been mapped for resistance to Pyrenophora teres $\mathrm{f}$. teres pathotypes prevalent around the world.

The objectives of this study were to identify markers closely linked to resistance to NTNB in 2 Australian barley mapping populations derived from crosses Tallon $\times$ Kaputar and VB9524 $\times$ ND11231, and to validate the markers in 2 other barley $\mathrm{DH}$ populations.

\section{Materials and methods}

\section{Mapping populations}

Mapping population Tallon/Kaputar (Cakir et al. 2003a, this issue) is described in detail elsewhere in this issue. The population VB9524/ ND11231 was developed by the barley breeding program of the Victorian Institute for Dryland Agriculture (L. C. Emebiri, unpublished data). The population was constructed by doubled haploidy using anther culture technique and included 180 lines.

\section{Disease response tests}

The DH lines and parents were grown in pots in a replicated experiment in the glasshouse. Ten plants of a single line were grown in each pot. Potting mix consisted of loam, peat, and vermiculite in the ratio $2: 1: 1$ (by vol.) to which was added a basal fertiliser of GF306N (Grow Force Australia) at $2.5 \mathrm{~kg} / \mathrm{m}^{3}$. After emergence, plants were fertilised weekly with Aquasol (Yates Australia) solution at $\sim 75 \mathrm{~mL} /$ pot. Seedlings were raised in a glasshouse where temperatures ranged from 10 to $25^{\circ} \mathrm{C}$ with a daylength around $12 \mathrm{~h}$.
Five isolates [NB50 from Gatton, Q1d; NB54 from Biloela Research Station, Qld; NB81 from Mt Rascal (near Toowoomba), Qld; NB97 from Byee (north of Kingaroy), Qld; and NB52B from South Australia] were used to screen the TK DH population. The VN population was screened with isolate NB77 (from Chinchilla, Qld). Each is a distinct isolate representing virulences from Australia (Gupta et al. 2003, this issue).

To prepare inoculum, single conidial cultures of each strain were increased on peanut oatmeal agar (Speakman and Pommer 1986) at $19^{\circ} \mathrm{C}$ under cool white and NUV light on a 12-h cycle. After 9 days in culture, conidia were washed from the agar surface, filtered through a $330-\mu \mathrm{m}$ strainer, and made up into an aqueous suspension containing $12500 \mathrm{conidia} / \mathrm{mL}$. Approximately $1.125 \mathrm{~mL}$ of this suspension was applied per pot with a Krebs airless paint sprayer (Oldfields Pty Ltd) when plants were at an average growth stage of 13.5 (Zadoks et al. 1974). Inoculated plants were immediately placed in a fogging chamber and held at $100 \%$ relative humidity for $24 \mathrm{~h}(14 \mathrm{~h}$ dark, $10 \mathrm{~h}$ light $)$ at $19^{\circ} \mathrm{C}$, then returned to the glasshouse for disease development. Notes on infection types (IT) were scored 9 days after inoculation using a scale developed by Tekauz (1985).

\section{Field trial}

Adult plant resistance in the TK population was assessed in a field nursery of $65 \mathrm{DH}$ lines and parents, sown in 2 replications in a randomised block design at Hermitage Research Station, Qld, in 1999. The trial site carried barley stubble infested with $P$. teres and a moderate epidemic developed. Disease levels were scored 10 days before anthesis, based on disease severity on a 1-9 scale where 1 was highly resistant and 9 was very susceptible.

\section{Marker analysis}

The genetic maps of the TK (Cakir et al. 2003a) and VN (L. C. Emebiri, unpublished data) populations utilising 263 and 250 DNA markers, respectively, were used to identify marker loci associated with resistance to NTNB. QTL analyses were performed using software packages MapManager QTX (Manly et al. 2001) and Qgene (Nelson 1997). A threshold LOD (logarithm of odds ratio) score of 3.0 was chosen for declaring the existence of a QTL. Wherever appropriate, simple regression and interval mapping analyses were used to identify the associations. Data for each isolate or site were analysed separately and a joint analysis over all strains/sites was performed for each trait.

\section{Validation of the markers}

Two DH populations, each comprising 300 lines, were constructed by anther culture. One population was derived from a cross between barley varieties Pompadour (FDO192/Patty) and Stirling (Dampier//Prior/ Ymer/3/Piroline) and the other from a cross between WPG8412 (Bowman//Ellice/TR451) and Stirling. These populations were screened with NTNB pathotypes from Western Australia (95NB100 and 97NB1) and Queensland (NB81) at the seedling stage using the screening procedure of Gupta and Loughman (2001). For the marker validation, bulk segregant analysis (BSA) was employed (Michelmore et al. 1991). Statistical analysis of the segregation data had identified the presence of a single resistance gene operative against all 3 isolates in both populations (S. Gupta, unpublished data). Based on this gene, DNA samples from 11 resistant and 11 susceptible lines for each population were mixed in equal proportions. The bulks and the parents from both crosses were assayed with a set of simple sequence repeat (SSR) markers and amplified fragment length polymorphism (AFLP) markers that had been mapped in the TK population. Genotyping conditions were the same as those reported by Cakir et al. (2003a) except that the genotyping of individual plants with SSR markers was carried out according to the method of Rampling et al. (2001). 


\section{Results}

\section{Tallon $\times$ Kaputar population}

\section{Resistance at the seedling stage}

The parent lines differed widely in their response to pathotypes NB54 and NB52B of NTNB (Table 1). The DH population showed a wide range of segregation for response to all pathotypes. Frequency distributions of infection types against NB54, NB52B, and NB97 indicated the presence of
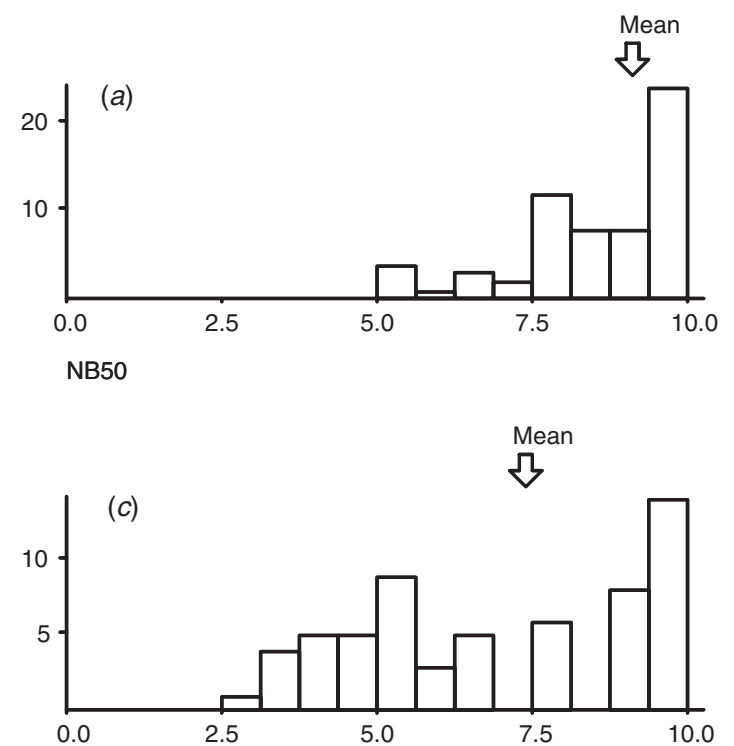

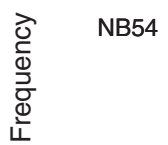
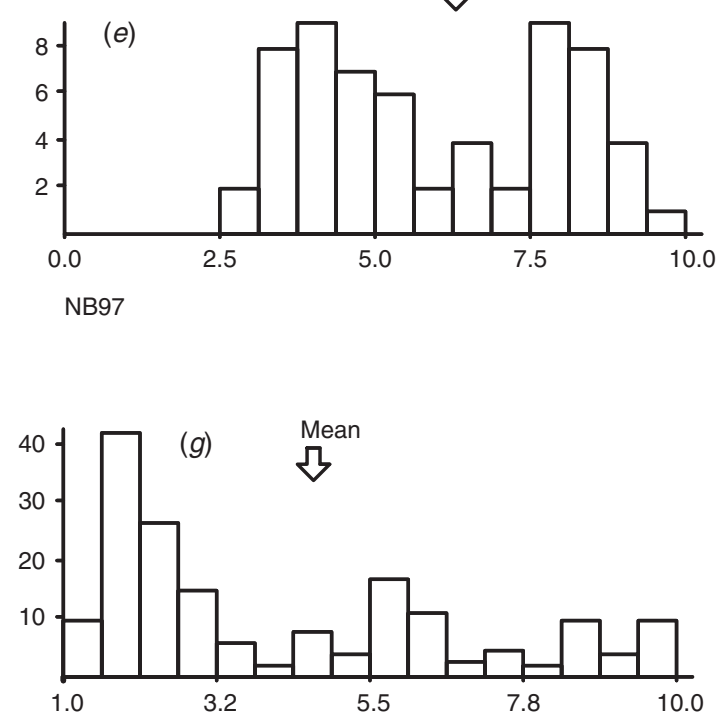

NB77 one major gene in the population (Fig. 1a). The presence of DH lines with intermediate ITs suggests the existence of additional genes with smaller effects. For all of the NTNB pathotypes, transgressive segregation was observed (Fig. 1a, Table 1).

Simple regression analysis identified markers highly significantly associated with each pathotype on chromosomes $2 \mathrm{H}, 3 \mathrm{H}$, and $6 \mathrm{H}$. For example, for pathotype NB97 there were 14 markers with a LOD score $>3.0$ on
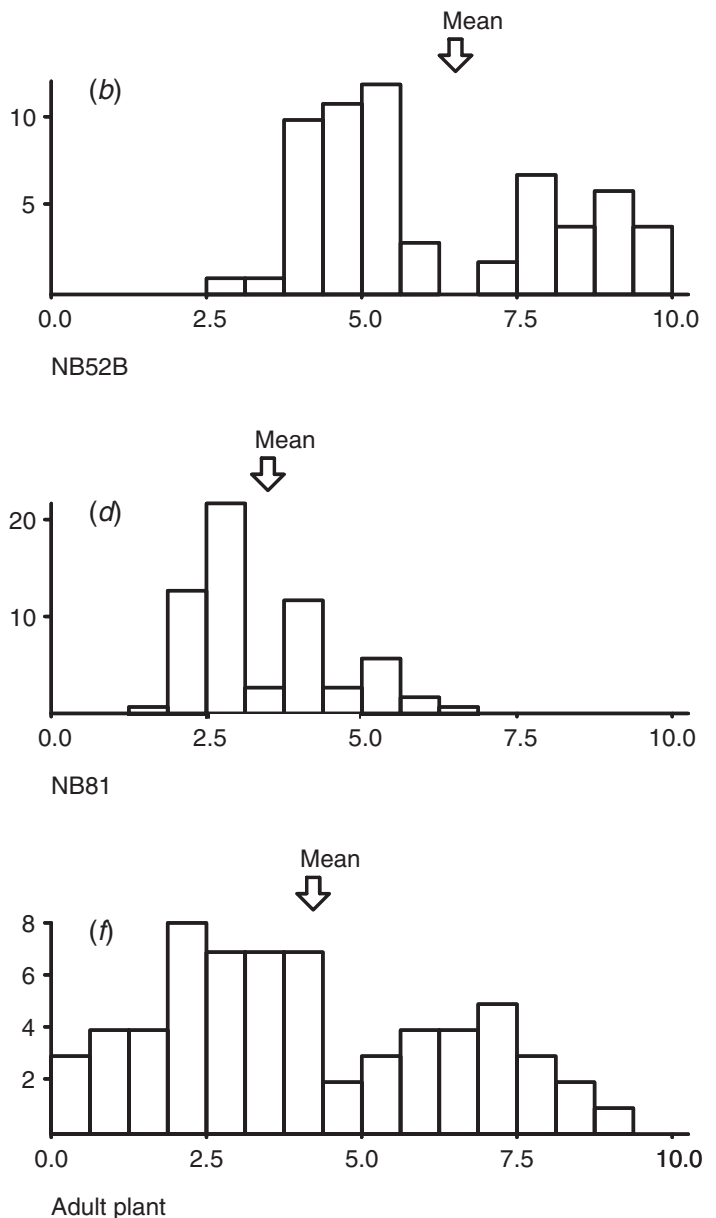

Fig. 1. Net type net blotch disease distributions for the pathotypes in TK population: $(a)$ B50, $(b)$ NB52B, (c) NB54, $(d)$ NB81, (e) NB97, $(f)$ adult plant scores, $(g)$ Disease distribution in the VN population for the pathotype NB77. Disease infection types at seedling stage were taken according to Tekauz (1985) using a 1-10 scale (1, resistant; 10, susceptible). Adult plant scoring was taken based on the disease severity using a 1-9 scale (1, resistant; 9 , susceptible). Arrows indicate the means of the DH lines. 
Table 1. Infection type scores of parental lines to the net blotch pathotypes at the seedling stage

\begin{tabular}{lcrcccc}
\hline Line & NB50 & NB52B & NB54 & NB77 & NB81 & NB97 \\
\hline Tallon & 9 & 6 & 10 & 8.5 & 4 & 8.5 \\
Kaputar & 6.5 & 5 & 4 & 5 & 2 & 5.5 \\
VB9524 & 8.5 & 10 & 8.5 & 9 & 4 & 8.5 \\
ND11231 & 4 & 1 & 3 & 1.5 & 1 & 2 \\
Pompadour & 3.5 & 3 & 7.5 & 2.5 & 1 & 2 \\
WPG8412 & 3.5 & 3 & 3 & 1 & 1 & 1 \\
Stirling & 8 & 5 & 5 & 4 & 5 & 3.5 \\
\hline
\end{tabular}

chromosome $6 \mathrm{H}$ and this result was consistent for all pathotypes. Overall, $R^{2}$ values for the significant markers on this chromosome ranged between $46 \%$ and $83 \%$, depending on the pathotype (Table 2). In particular the SSR marker Bmag0381 had the highest LOD score and $R^{2}$ values for the pathotypes NB52B, NB54, NB81, and NB97. $R^{2}$ and LOD score for pathotype NB97 were $83 \%$ and 22.79 , respectively (Table 2). For NB50, M61P12K116 was the most significant marker, with an $R^{2}$ of $65 \%$.

Genetic data for SSR marker Bmag0381 showed a complete co-segregation with the disease data in the

Table 2. Markers associated with resistance to net type net blotch (NB97 for the TK population and NB77 for the $\mathrm{VN}$ population) on chromosomes $2 \mathrm{H}, 3 \mathrm{H}$, and $6 \mathrm{H}$, their values for $\boldsymbol{R}^{2}$, LOD scores, and probability in Tallon $\times$ Kaputar (TK) and VB9524 $\times$ ND11231 (VN) populations

\begin{tabular}{|c|c|c|c|c|c|c|c|c|}
\hline Marker & Chrom. & Pop. & $R^{2, \mathrm{~A}}$ & $\mathrm{LOD}^{\mathrm{B}}$ & $P$ & $\mathrm{AA}^{\mathrm{C}}$ & $\mathrm{aa}^{\mathrm{C}}$ & $\mathrm{Add}^{\mathrm{D}}$ \\
\hline Bmag0114 & $2 \mathrm{H}$ & TK & 0.29 & 4.59 & 0.0000 & 6.64 & 4.36 & 1.14 \\
\hline $\mathrm{p} 11 \mathrm{~m} 54 \mathrm{~T} 105$ & $2 \mathrm{H}$ & TK & 0.24 & 3.62 & 0.0001 & 6.56 & 4.45 & 1.05 \\
\hline EBmac0607 & $2 \mathrm{H}$ & TK & 0.23 & 3.46 & 0.0001 & 6.51 & 4.45 & 1.03 \\
\hline EBmac0623 & $2 \mathrm{H}$ & TK & 0.22 & 3.34 & 0.0001 & 6.49 & 4.45 & 1.02 \\
\hline p13m62KT134 & $2 \mathrm{H}$ & $\mathrm{TK}$ & 0.22 & 3.05 & 0.0002 & 6.53 & 4.50 & 1.01 \\
\hline EBmac0623 & $2 \mathrm{H}$ & $\mathrm{TK}$ & 0.22 & 3.34 & 0.0001 & 6.49 & 4.45 & 1.02 \\
\hline p13m62KT134 & $2 \mathrm{H}$ & TK & 0.21 & 3.05 & 0.0002 & 6.53 & 4.50 & 1.01 \\
\hline p11m47TK118 & $3 \mathrm{H}$ & TK & 0.31 & 4.92 & 0.0000 & 6.81 & 4.56 & 1.12 \\
\hline p13m47KT191 & $3 \mathrm{H}$ & $\mathrm{TK}$ & 0.25 & 3.71 & 0.0000 & 6.68 & 4.63 & 1.02 \\
\hline Bmag0381 & $6 \mathrm{H}$ & TK & 0.83 & 22.79 & 0.0000 & 7.78 & 4.11 & 1.83 \\
\hline $\mathrm{p} 12 \mathrm{~m} 61 \mathrm{~K} 116$ & $6 \mathrm{H}$ & TK & 0.70 & 15.71 & 0.0000 & 7.45 & 4.09 & 1.68 \\
\hline Bmac0018 & $6 \mathrm{H}$ & $\mathrm{TK}$ & 0.70 & 15.91 & 0.0000 & 7.50 & 4.15 & 1.67 \\
\hline HVM31 & $6 \mathrm{H}$ & TK & 0.70 & 15.28 & 0.0000 & 7.43 & 4.09 & 1.67 \\
\hline Bmag0173 & $6 \mathrm{H}$ & TK & 0.70 & 15.25 & 0.0000 & 7.40 & 4.09 & 1.65 \\
\hline EBmac0874 & $6 \mathrm{H}$ & $\mathrm{TK}$ & 0.69 & 14.88 & 0.0000 & 7.60 & 4.33 & 1.63 \\
\hline p11m54T416 & $6 \mathrm{H}$ & TK & 0.68 & 14.47 & 0.0000 & 7.43 & 4.19 & 1.62 \\
\hline HVM74 & $6 \mathrm{H}$ & TK & 0.65 & 12.11 & 0.0000 & 7.32 & 4.15 & 1.58 \\
\hline $\mathrm{p} 13 \mathrm{~m} 55 \mathrm{~K} 072$ & $6 \mathrm{H}$ & $\mathrm{TK}$ & 0.65 & 12.97 & 0.0000 & 7.42 & 4.19 & 1.61 \\
\hline p13m54K261 & $6 \mathrm{H}$ & TK & 0.63 & 12.69 & 0.0000 & 7.37 & 4.20 & 1.58 \\
\hline p12m61T207 & $6 \mathrm{H}$ & TK & 0.55 & 10.56 & 0.0000 & 7.27 & 4.29 & 1.48 \\
\hline $\mathrm{p} 13 \mathrm{~m} 48 \mathrm{~T} 151$ & $6 \mathrm{H}$ & TK & 0.55 & 10.10 & 0.0000 & 7.23 & 4.22 & 1.50 \\
\hline p12m61T169 & $6 \mathrm{H}$ & TK & 0.48 & 8.63 & 0.0000 & 7.38 & 4.58 & 1.39 \\
\hline $\mathrm{p} 13 \mathrm{~m} 55 \mathrm{~T} 311$ & $6 \mathrm{H}$ & TK & 0.46 & 8.01 & 0.0000 & 7.25 & 4.55 & 1.35 \\
\hline P11M48_160 & $6 \mathrm{H}$ & $\mathrm{VN}$ & 0.66 & 41.31 & 0.0000 & 6.73 & 2.50 & 2.11 \\
\hline P11M53_88 & $6 \mathrm{H}$ & VN & 0.62 & 36.09 & 0.0000 & 6.64 & 2.56 & 2.03 \\
\hline Bmag0173 & $6 \mathrm{H}$ & $\mathrm{VN}$ & 0.60 & 33.14 & 0.0000 & 6.66 & 2.66 & 2.00 \\
\hline P13M48_161 & $6 \mathrm{H}$ & VN & 0.42 & 20.07 & 0.0000 & 6.04 & 2.71 & 1.66 \\
\hline P14M62_116 & $6 \mathrm{H}$ & $\mathrm{VN}$ & 0.40 & 18.78 & 0.0000 & 6.01 & 2.76 & 1.62 \\
\hline P14M62_85 & $6 \mathrm{H}$ & $\mathrm{VN}$ & 0.36 & 16.45 & 0.0000 & 6.00 & 2.91 & 1.54 \\
\hline P14M48_246 & $6 \mathrm{H}$ & $\mathrm{VN}$ & 0.36 & 16.11 & 0.0000 & 5.96 & 2.84 & 1.55 \\
\hline P13M48_105 & $6 \mathrm{H}$ & VN & 0.34 & 15.69 & 0.0000 & 6.16 & 3.08 & 1.53 \\
\hline Est701_2 & $6 \mathrm{H}$ & $\mathrm{VN}$ & 0.34 & 15.56 & 0.0000 & 5.83 & 2.83 & 1.50 \\
\hline P11M52_260 & $6 \mathrm{H}$ & $\mathrm{VN}$ & 0.30 & 13.49 & 0.0000 & 5.78 & 2.96 & 1.40 \\
\hline P13M48_152 & $6 \mathrm{H}$ & $\mathrm{VN}$ & 0.29 & 12.58 & 0.0000 & 5.69 & 2.91 & 1.38 \\
\hline P14M49_192 & $6 \mathrm{H}$ & $\mathrm{VN}$ & 0.23 & 10.00 & 0.0000 & 5.60 & 3.12 & 1.23 \\
\hline
\end{tabular}

${ }^{\text {A }}$ Phenotypic variation explained by each marker.

${ }^{\mathrm{B}}$ Logarithm of odds ratio.

${ }^{\mathrm{C}}$ Disease severity mean of the DH lines within each genotypic class; AA and aa indicate the first and the second parents, respectively.

${ }^{\mathrm{D}}$ Additive effect of replacing one allele (a) with the other (A). 


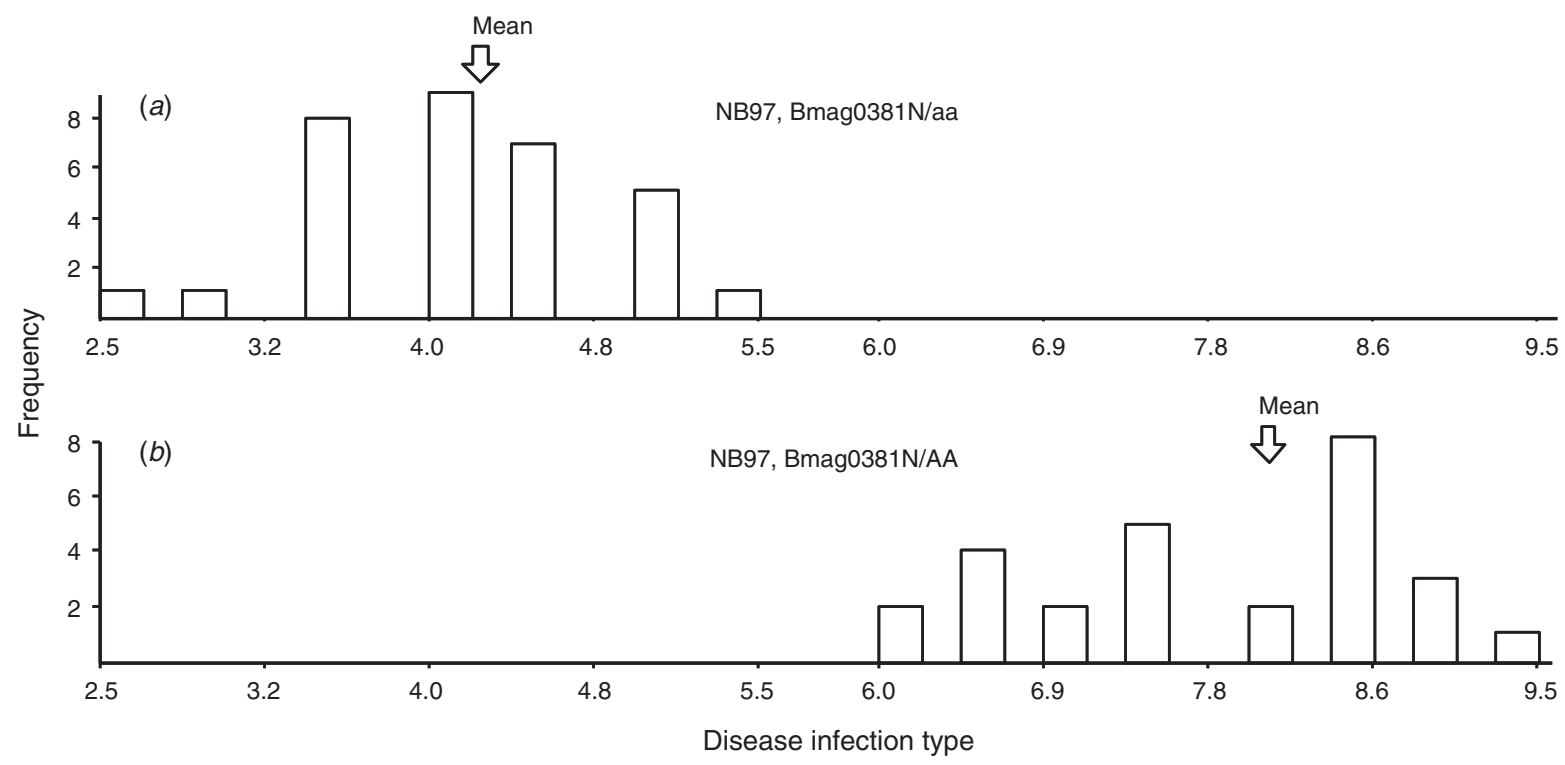

Fig. 2. Frequency distributions for the NTNB infection type scores of pathotype NB97 in the DH lines carrying alleles from (a) Tallon, and (b) Kaputar at the SSR locus Bmag0381. The arrows indicate the means of each genotypic class.

mapping population (Fig. 2), indicating a very tight linkage to the NTNB resistance gene on chromosome $6 \mathrm{H}$. AFLP marker M61P12K116 and SSR marker Bmag0173 had only 3 recombinant lines with the disease resistance gene, indicating tight linkage with this gene (results not shown).

The second QTL region near the centromere of chromosome $2 \mathrm{H}$ was found to be linked to a gene for resistance to NTNB. This QTL accounted for $20-29 \%$ of the variation in disease reaction, depending on the pathotype, with the highest $R^{2}$ of $29 \%$ for NB97 (Table 2). For pathotypes NB52B, NB54, NB81, and NB97, the SSR marker Bmag0114 was the most significant. AFLP marker M47P13T109 had the highest $R^{2}$ value for the pathotype NB50 (results not shown). The third QTL was located on the short arm of chromosome $3 \mathrm{H}$. The region between markers p11m47TK118 and p13m47KT191 showed a high level of association with low disease response from the pathotype
NB97, with an $R^{2}$ value of $31 \%$ (Table 3 ). $R^{2}$ values of disease response data from other pathotypes ranged from $24 \%$ to $30 \%$ (results not shown).

\section{Resistance at the adult plant stage}

Analysis of the adult plant data revealed the same $6 \mathrm{H}$ QTL to be the most significant region. In this QTL region, EBmac0874 SSR marker had the highest $R^{2}$ value $\left(R^{2}=65 \%\right)$. The second most important marker was M61P12K116 $\left(R^{2}=56 \%\right)$ (Table 3).

\section{VB9524 × ND11231 population}

Infection types of parental lines tested differed markedly with all pathotypes, except NB81, where VB9524 was not fully susceptible (Table 1). Population ITs revealed a distribution that was somewhat biomodal, indicating the presence of 1 major gene (Fig. $1 g$ ). Marker analysis

Table 3. The most significant marker intervals linked to resistance to net type net blotch (NB97 isolate for the TK population and NB77 isolate for the VN population), their chromosomal locations, interval sizes (cM), values for $R^{2}$, and LOD scores in Tallon $\times$ Kaputar (TK) and VB9524 × ND11231 (VN) populations

\begin{tabular}{lccccr}
\hline Marker & Population & Chrom. & Interval size & $R^{2, \mathrm{~A}}$ & LOD $^{\mathrm{B}}$ \\
\hline Bmag0114- p11m54T105 & TK & 2H & 1.5 & 0.29 & 4.59 \\
p13m47KT191-p11m47TK118 & TK & $3 \mathrm{H}$ & 2.0 & 0.31 & 5.04 \\
Bmag0381-EBmac0874 & TK & $6 \mathrm{H}$ & 1.7 & 0.83 & 22.78 \\
EBmac0874-p12m61K116 & TK & $6 \mathrm{H}$ & 3.4 & 0.65 & 13.71 \\
& (adult plant) & & & & \\
P11M48_160-p11m53_88 & VN & $6 \mathrm{H}$ & 4.8 & 0.66 & 41.31 \\
\hline
\end{tabular}

APhenotypic variation explained by the most significant marker.

${ }^{\mathrm{B}}$ Logarithm of odds ratio. 

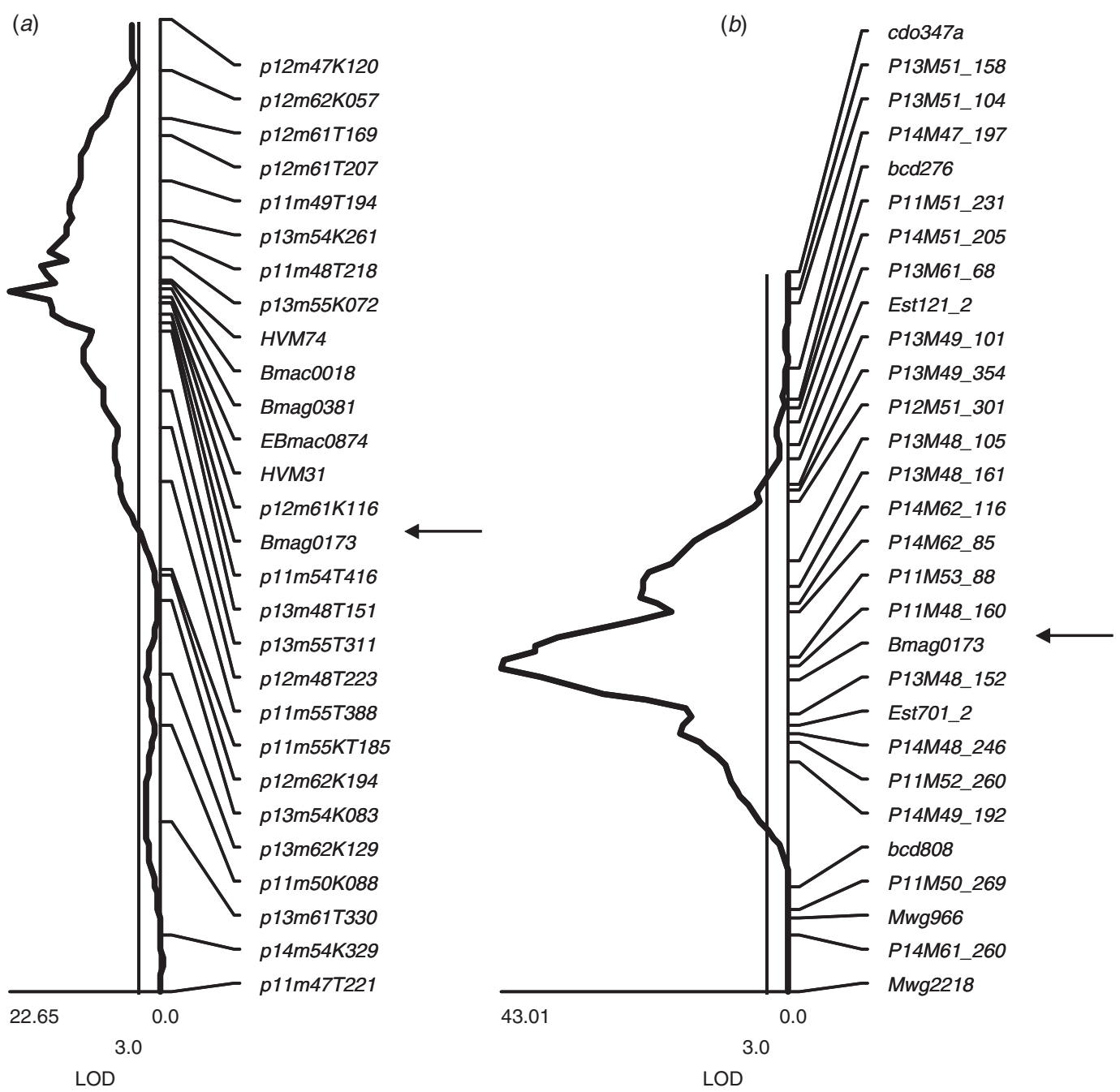

Fig. 3. Interval mapping analysis of NTNB trait data for chromosome $6 \mathrm{H}$ in $(a) \mathrm{TK}$, and $(b) \mathrm{VN}$ populations. For this figure, data from the NB54 pathotype were used for the TK population. The map was constructed by using MapManager QTX software and the interval analysis was conducted by Qgene software. The line at LOD 3.0 indicates the threshold level of highly significant markers. The arrow indicates the common marker Bmag0173.

indicated the presence of a major gene resulting in only 1 strong QTL on chromosome $6 \mathrm{H}$, which corresponded to the same region identified in the TK population (Fig. $3 a, b$ ). Single marker analysis revealed 12 markers with a LOD score $>3.0$ (Table 2). The most significant marker (p11m48_160) in this QTL explained 66\% of the phenotypic variation for NTNB response in this population.

\section{Validation of $6 H$ QTL}

Two AFLP and 2 SSR markers (M61P12K116, M55P13T311, Bmag0173, and EBmac0874) known to be located on $6 \mathrm{H}$ showed clear polymorphisms between parents and the bulks of Pompadour $\times$ Stirling and WPG8412 $\times$ Stirling populations (results not shown). Three of these markers were then assayed for the individual lines within these bulks. All of the individuals within resistant bulks and susceptible bulks exhibited complete association with the markers M55P13T311 and Bmag0173. For the AFLP marker M61P12K116, all but 3 individuals from the susceptible bulk showed the expected banding pattern. This validation analysis further confirmed the presence of a major QTL for the NTNB resistance on chromosome $6 \mathrm{H}$.

\section{Discussion}

Plants with IT of 5 and below were considered resistant, whereas those with IT $>5$ were considered susceptible. There was distinct segregation within the TK-population for response to NB97, NB52B, and NB54 pathotypes. Pathotypes NB97 and NB52B showed a near 1:1 segregation for the resistant and susceptible lines, indicating the presence of one major gene. The presence of transgressive segregants and the DH lines with intermediate infection 
types for all pathotypes suggest the presence of additional minor genes for resistance in the parents. Steffenson et al. (1996) also observed transgressive segregation for net blotch severity in a Steptoe $\times$ Morex $\mathrm{DH}$ population. Additional studies need to be done to identify the location of these minor genes.

None of the lines in the population was resistant to pathotype NB50 because both parents (Tallon and Kaputar) were susceptible to this pathotype. In contrast, only 4 lines were susceptible to the NB81 pathotype. The resistant reaction of both parents and most of the lines to NB81 indicates that there is either a common resistance gene in Tallon and Kaputar or additional gene(s) for resistance to this pathotype in Tallon. The resistance gene, located on $6 \mathrm{H}$ chromosome and confirmed in validation populations, appears to be from Tallon. Molecular genetic analysis of screening data with pathotype NB81 in the validation populations confirmed that resistance in Tallon is the same as in Pompadour and WPG8412 parental lines. Resistance to other pathotypes used in tests on the TK population were also mapped on the same region of chromosome $6 \mathrm{H}$; a resistance locus from the parent Kaputar is also located on chromosome $6 \mathrm{H}$. Further experiments are needed to determine if the resistance loci in the parental lines Tallon and Kaputar are the same loci for the NB81 pathotype.

Five of the 6 isolates used in this study were from Queensland and represented 5 different pathotypes (Platz et al. (2000). Two isolates used in the validation experiment were from Western Australia (Gupta and Loughman 2001) and one from Queensland. Our data indicated that one common resistance gene was effective against all of these pathotypes. In a similar experiment, Afanasenko et al. (2000) used NTNB isolates collected from different countries around the world to study resistance. Their findings in an $\mathrm{F}_{2}$ population suggested the presence of one common dominant gene operating against all isolates and additive resistance genes specific to individual isolates. These studies indicated that common genes can be effective against a wide range of pathotypes of $P$. teres $\mathrm{f}$. teres (Tekauz 1990; Afanasenko et al. 2000; Platz et al. 2000). Molecular work is currently underway to find markers linked to the additional resistance genes in our validation populations.

Comparative mapping, based on common markers among genetic maps, allows comparison of QTLs for a given trait among different populations. The QTL reported on chromosome $6 \mathrm{H}$ in this study appears to be located at the same region of chromosome $6 \mathrm{H}$ in at least 2 other studies (Steffenson et al. 1996; Manninen et al. 2000). However, in the absence of markers common among these studies it cannot be concluded that these QTL regions represent the same resistance genes.

The use of BSA with polymorphic markers from a genetic map in a different population allowed us to comparatively map a trait and validate the chromosomal location of a gene in barley populations without a saturated genetic map of the subsequent population. BSA was first used to identify markers for disease resistance genes in lettuce species (Michelmore et al. 1991). Since then the technique has been used in many studies for identification of markers in different crop species such as apple (Yang et al. 1997), grapevine (Lahogue et al. 1998), and maize (Quarrie et al. 1999). A similar approach to ours identified 4 markers closely linked to the Rsv1 locus of soybean mosaic virus (Hayes and Saghai Maroof 2000). They first identified the markers by BSA then mapped it on a segregating population to find the location of the markers.

This study indicated that the QTLs identified on $2 \mathrm{H}, 3 \mathrm{H}$, and $6 \mathrm{H}$ gave effective seedling resistance and that the $6 \mathrm{H}$ QTL also conferred resistance to a field isolate at the adult plant stage. This result agrees with the inheritance studies of Gupta et al. (2002). They found that the gene on chromosome $6 \mathrm{H}$ conferred resistance to NTNB in both seedling and adult plant stages in 3 different barley $\mathrm{DH}$ populations. It has been reported that some genes function only in adult plants (Tekauz 1990; Douiyssi et al. 1998). We have observed in another barley $\mathrm{DH}$ population that some lines that were susceptible to pathotype NB321 (which is prevalent in Q1d) at the seedling stage showed high levels of resistance at the adult plant stage (G. J. Platz, unpublished data). Similarly, Steffenson et al. (1996) identified different QTLs for resistance to $P$. teres during the seedling stage and adult plant stage. Richter et al. (1998) detected different numbers of QTLs from disease response data taken on the first and second seedling leaves. They found that different genes were expressed, depending on the period from inoculation to observation of disease response. From these studies it appears that some genes are expressed during both the seedling and adult plant stages, whereas other genes are expressed at only the seedling or the adult plant stage. It is also possible that differences in resistance between seedlings and adults may be pathotype-specific.

The QTL region detected on chromosome $6 \mathrm{H}$ spanned a large chromosomal segment in both populations (Fig. 3). In this region, there were 6 SSRs and 11 AFLP markers in the TK population and 12 markers (1 SSR, 10 AFLP, and 1 expressed sequence tag) in the VN population. Bmag0173 was the common marker between both populations. Strong linkage between the disease resistance gene and marker Bmag0173 in both populations indicates that both populations have the same resistance gene on chromosome 6H. SSR marker Bmag0381 completely co-segregated with the disease data in the TK population (Fig. 2) and we believe that the NTNB resistance gene must be tightly linked to this marker. The parents used in the validation populations and VN population were not polymorphic for marker Bmag0381, and we were therefore unable to test it in those populations. Among the markers that were validated, Ebmag0874 was $1.7 \mathrm{cM}$ away from Bmag0381. Bmag0173 and 
M61P12K116 markers, which were completely linked to each other, were $5.1 \mathrm{cM}$ from Bmag0381.

Having multiple markers linked to low disease response in each QTL region offers a good opportunity for plant breeders to use markers to select for resistance to NTNB. This increases the chances of having an ample number of polymorphisms in a wide range of parental germplasm. SSR markers used in this study generally had high levels of polymorphic information content in a study of European barley germplasm (Macaulay et al. 2001). For this reason, SSR markers Bmag0173 and Bmag0381 may prove to be very useful markers for breeding programs. We are also currently testing other SSR markers and the conversion of AFLP markers into sequence characterised amplified region markers, with the ultimate aim of developing single nucleotide polymorphism markers for high throughput screening in breeding programs.

DNA markers are being used as selection tools in breeding programs throughout Australia (Barr et al. 2000, Cakir 2003b). This work has identified several markers that are associated with resistance to NTNB. The chromosomal regions in which these markers are located will be focal points of further research and the validation and implementation of markers for routine selection in breeding programs. The markers located in these regions could also be used in pedigree-based association mapping studies using diverse barley genetic resources.

\section{Acknowledgments}

We thank Sue Broughton for developing the DH lines used for the validation experiment, and Julie Uhlmann for her technical assistance in the laboratory. Funding for this research is provided by GRDC through the National Barley Molecular Marker Program. We are grateful to the Western Australian State Agricultural Biotechnology Centre for providing laboratory facilities, and the Scottish Crop Research Institute for providing the SSR markers.

\section{References}

Afanasenko OS, Levitin MM (1979) The population structure of the pathogen of net blotch of barley as regards its virulence. I. Identification of races. Mikological Fitopatology 13, 230-234.

Afanasenko OS, Makarova IG, Zubkovich AA (1999) The number of genes controlling resistance to Pyrenophora teres Drechs. strains in barley. Russian Journal of Genetics 35, 274-283.

Afanasenko O, Makarova I, Zubkovich A (2000) Inheritance of resistance to different Pyrenophora teres Dreschs. strains in barley accession CI 5791. In 'Proceedings of 8th International Barley Genetics Symposium'. Vol. 2, pp. 73-74. (Dept of Plant Science, Adelaide University: Glen Osmond, S. Aust.)

Barr AR, Jefferies SP Warner P, Moody DB, Chalmers KJ, Langridge P (2000) Marker assisted selection in theory and practice. In 'Proceedings of 8th International Barley Genetics Symposium'. Vol. I, pp. 167-178. (Dept of Plant Science, Adelaide University: Glen Osmond, S. Aust.)
Buchannon KW, McDonald WC (1965) Sources of resistance in barley to Pyrenophora teres. Canadian Journal of Plant Science 87, 11401143.

Cakir M, Poulsen D, Galwey NW, Ablett GA, Chalmers KJ, Platz GJ, Park RF, Lance RCW, Panozzo JF, Read BJ, Moody DB, Barr AR, Johnston P, Li CD, Boyd WJR, Grime CR, Appels R, Jones MGK, Langridge P (2003a) Mapping and QTL analysis of the barley population Tallon $\times$ Kaputar. Australian Journal of Agricultural Research 54, 1155-1162.

Cakir M, Appels R, Carter M, Loughman R, Francki M, Li C, Johnson J, Bhave M, Wilson R, McLean R, Barclay I (2003b). Accelerated wheat breeding using molecular markers. In 'Proceedings of 10th International Wheat Genetics Symposium'. Vol. 1, pp. 117-120. (Istituto Sperimentale per la Cerealicolture: Roma, Italy)

Douiyssi A, Rasmusson DC, Roelfs AP (1998) Responses of barley cultivars and lines to isolates of Pyrenophora teres. Plant Disease 82, 316-321.

Douiyssi A, Rasmusson DC, Wilcoxson RD (1996) Inheritance of resistance to net blotch in barley in Morocco. Plant Disease 80, $1269-1272$.

Graner A, Foroughi-Wehr B, Tekauz A (1996) RFLP mapping of a gene in barley conferring resistance to net blotch (Pyrenophora teres). Euphytica; Netherlands Journal of Plant Breeding 91, 229-234.

Gupta S, Loughman R (2001) Current virulence of Pyrenophora teres on barley in Western Australia. Plant Disease 85, 960-966.

Gupta S, Loughman R, Cakir M, Platz G, Li C, Lance R, Jones MGK, Appels R (2002) Genetic and molecular studies of seeding and adult plant resistance in barley against Pyrenophora teres f. teres. In 'Proceedings of 2nd International Workshop on Barley Leaf Blights'. ICARDA, Aleppo, Syria (in press).

Gupta S, Loughman R, Platz GJ, Lance RCM (2003) Resistance in cultivated barleys to Pyrenophora teres f. teres and prospects of its utilisation in marker identification and breeding. Australian Journal of Agricultural Research 54, 1379-1386.

Hayes AJ, Saghai Maroof MA (2000) Targeted resistance gene mapping in soybean using modified AFLPs. Theoretical and Applied Genetics 100, 1279-1283. doi:10.1007/S001220051435.

Ho KM, Tekauz A, Choo TM, Martin RA (1996) Genetic studies on net blotch resistance in a barley cross. Canadian Journal of Plant Science 76, 715-719.

Jonsson R, Sall T, Kraft T, Gustafsson M (1999) Inheritance of resistance to Pyrenophora teres $\mathrm{f}$. teres in spring barley. Plant Breeding 118, 313-317. doi:10.1046/J.1439-0523.1999.00380.X.

Khan TN (1987) Relationship between net blotch (Drechslera teres) and losses in grain yield of barley in Western Australia. Australian Journal of Agricultural Research 38, 671-679.

Khan TN, Boyd WJ (1969) Inheritance of resistance to net blotch in barley. II. Genes conditioning resistance against race W.A.-2. Canadian Journal of Genetical Cytology 11, 592-597.

Khan TN, Tekauz A (1982) Occurrence and pathogenicity of Drechslera teres isolates causing spot-type symptoms on barley in Western Australia. Plant Disease 66, 423-425.

Lahogue F, This P, Bouquet A (1998) Identification of a codominant scar marker linked to the seedlessness character in grapevine. Theoretical and Applied Genetics 97, 950-959. doi:10.1007/ S001220050976.

Macaulay M, Ramsay L, Powell W, Waugh R (2001) A representative, highly informative 'genotyping set' of barley SSRs. Theoretical and Applied Genetics 102, 801-809. doi:10.1007/S001220000487.

Manly KF, Cudmore RH Jr, Meer JM (2001) Map Manager QTX, crossplatform software for genetic mapping. Mammalian Genome 12, 930-932. doi:10.1007/S00335-001-1016-3.

Manninen O, Kalendar R, Robinson J, Schulman AH (2000) Application of $B A R E-1$ retrotransposon markers to the mapping of 
a major gene for net blotch in barley. Molecular and General Genetics 264, 325-334. doi:10.1007/S004380000326.

Michelmore RW Paran I, Kesseli RV (1991) Identification of markers linked to disease resistance gene by bulked segregant analysis: a rapid method to detect markers in specific genomic regions by using segregating populations. Proceedings of National Academy Sciences USA 88, 9828-9832.

Nelson JC (1997) QGENE: software for marker-based genomic analysis and breeding. Molecular Breeding 3, 239-245. doi:10.1023/A:1009604312050.

Platz G, Bell KL, Rees RG, Galea VJ (2000) Pathotype variation of the Australian net blotch populations. In 'Proceedings of 8 th International Barley Genetics Symposium'. Vol. 2, pp. 182-183. (Dept of Plant Science, Adelaide University: Glen Osmond, S. Aust.)

Pon DS (1949) Physiologic specialization and variation in Helminthosporium teres. (Abstr.). Phytopathology 38, 18-18.

Quarrie SA, Lazic-Jancic V, Kovacevic D, Steed A, Pekic S (1999) Bulk segregant analysis with molecular markers and its use for improving drought resistance in maize. Journal of Experimental Botany 50, 1299-1306. doi:10.1093/JEXBOT/50.337.1299.

Rampling LR, Harker N, Shariflou MR, Morell MK (2001) Detection and analysis systems for microsatellite markers in wheat. Australian Journal of Agricultural Research 52, 1131-1141. doi:10.1071/ AR01027.

Richter K, Schondelmaier J, Jung C (1998) Mapping of quantitative trait loci affecting Drechslera teres resistance in barley with molecular markers. Theoretical and Applied Genetics 97, 1225 1234. doi:10.1007/S001220051014.

Smedegard-Petersen V (1971) Pyrenophora teres f. maculata f. nov. and Pyrenophora teres f. teres on barley in Denmark. Yearbook. pp. 124-144. (Royal Veterinary Agricultural University: Copenhagen)
Spaner D, Shugar LP, Choo TM, Falak I, Briggs KG, Legge WG, Falk DE, Ullrich SE, Tinker NA, Steffenson BJ, Mather DE (1998) Mapping of disease resistance loci in barley on the basis of visual assessment of naturally occuring sypmtoms. Crop Science 38, 843850 .

Speakman JB, Pommer EH (1986) A simple method for producing large volumes of Pyrenophora teres spore suspension. Bulletin of the British Mycological Society 20(2), 129.

Steffenson BJ, Hayes PM, Kleinhofs A (1996) Genetics of seedling and adult plant resistance to net blotch (Pyrenophora teres $f$. teres) and spot blotch (Cochliobolus sativus) in barley. Theoretical and Applied Genetics 92, 552-558. doi:10.1007/S001220050162.

Steffenson BJ, Webster RK (1992) Pathotype diversity of Pyrenophora teres f. teres on barley. Phytopathology 82, 170-177.

Tekauz A (1985) A numerical scale to classify reactions of barley to Pyrenophora teres. Canadian Journal of Plant Pathology 7, 181183.

Tekauz A (1990) Characterization and distribution of pathogenic variation in Phrenophora teres f.sp. teres and P. teres f.sp. maculata from Western Canada. Canadian Journal of Plant Pathology 12, $141-148$.

Wilcoxson RD, Rasmusson DC, Treeful LM, Suganda T (1992) Inheritance of resistance to Pyrenophora teres in Minnesota barley. Plant Disease 76, 367-369.

Yang HY, Korban SS, Kruger J, Schmidt H (1997) The use of a modified bulk segregant analysis to identify a molecular marker linked to a scab resistance gene in apple. Euphytica 94, 175-182. doi:10.1023/A:1002998121106.

Zadoks JC, Chang TT, Konzak CF (1974) A decimal code for the growth stages of cereals. Weed Research 14, 415-421.

Manuscript received 2 December 2002, accepted 11 August 2003 